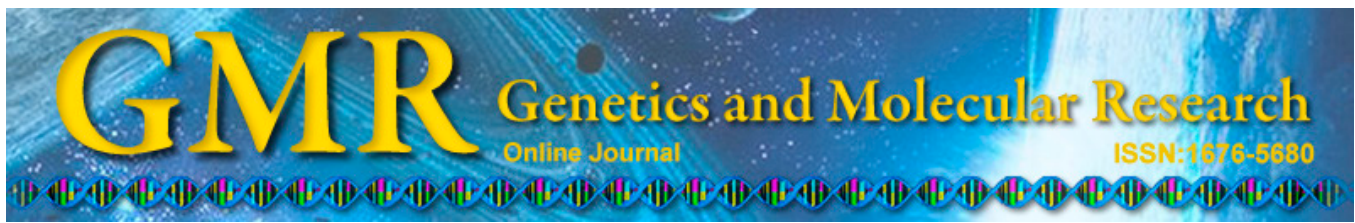

\title{
Cloning and expression analysis of a heat shock protein $90 \beta$ isoform gene from the gills of Wuchang bream (Megalobrama amblycephala Yih) subjected to nitrite stress
}

S.M. Sun ${ }^{1}$, J. Zhu' ${ }^{1}$ X.P. Ge ${ }^{1}$, C.F. Zhang ${ }^{1}$, L.H. Miao ${ }^{1}$ and X.J. Jiang ${ }^{2}$

${ }^{1}$ Key Laboratory of Freshwater Fisheries and Germplasm Resources Utilization, Ministry of Agriculture, Freshwater Fisheries Research Center, Chinese Academy of Fishery Sciences, Wuxi, China

${ }^{2}$ Wuxi Fishery College Nanjing Agricultural University, Wuxi, China

Corresponding author: J. Zhu

E-mail: zhuj@ffrc.cn

Genet. Mol. Res. 14 (2): 3036-3051 (2015)

Received May 10, 2014

Accepted September 25, 2014

Published April 10, 2015

DOI http://dx.doi.org/10.4238/2015.April.10.14

ABSTRACT. Heat shock protein 90 (HSP90), a highly conserved
and multi-functional molecular chaperone, plays an essential role in
cellular metabolism and stress response. In this study, HSP90 cDNA
named MaHSP90 was cloned from Wuchang bream (Megalobrama
amblycephala) gills by using rapid amplification of cDNA ends. The full-
length MaHSP90 cDNA is 2674 bp and consists of a 3',5'-untranslated
region and a 2250 -bp open reading frame encoding a 750 -amino acid
long protein. Identity analysis revealed that the amino acid sequence
of MaHSP90 is highly conserved. Homology analysis and structure
comparison further indicated that MaHSP90 should be the $\beta$ isoform
member of the HSP90 family. MaHSP90 mRNA was ubiquitously
expressed in the liver, heart, muscle, gill, intestine, kidney, and brain.
The MaHSP90 mRNA levels under nitrite stress were analyzed using
real-time quantitative reverse transcriptase-polymerase chain reaction 
(qRT-PCR); the mRNA levels significantly increased at 3, 6, and $12 \mathrm{~h}$ after nitrite exposure in the gills and then stabilized between 24 and 48 h. Furthermore, a similar relationship between mRNA expression (qRTPCR) and HSP90 protein levels (densitometric band analysis) was found. Transcriptional analysis of caspase- 8 and caspase- 9 expression in the gills of juvenile M. amblycephala after a 48-h exposure to nitrite suggested that MaHSP90 expression is related positively with nitriteinduced apoptosis. Fish exposed to nitrite also showed gill damage. Our results suggest that MaHSP90 mRNA is constitutively expressed in various tissues and inducible in the gills under nitrite stress, suggesting its important role in nitrite stress response.

Key words: Megalobrama amblycephala; Expression pattern; Gill; Nitrite exposure; HSP90

\section{INTRODUCTION}

Heat shock proteins (HSPs), ubiquitously distributed and evolutionarily conserved proteins, are found in a variety of living organisms. They exert a protective effect against a variety of stressful stimuli (Lindquist and Craig, 1988). HSPs are grouped into several families according to their molecular size and functions: HSP110, HSP90, HSP70, HSP60, HSP47, and low molecular mass HSPs. Among them, HSP90 is a highly conserved and abundant cytosolic protein that accounts for $1-2 \%$ of the total proteins in a normal cell. Multiple functions have been assigned to HSP90, such as protein folding, cell signaling, and protein degradation, in both normal metabolism and protecting organisms under stressful conditions (Gething and Sambrook, 1992; Pratt and Toft, 2003; Pearl and Prodromou, 2006; Fu et al., 2011). There are two cytoplasmic isoforms of HSP90, namely HSP90 $\alpha$ (inducible type) and HSP90 $\beta$ (constitutive type) in cells (Sreedhar et al., 2004). HSP90 $\beta$ lacks the glutamine-rich sequence (QTQDQ) at the N-terminus and is larger than HSP90 $\alpha$, whereas they exhibit different molecular chaperone functions (Lees-Miller and Anderson, 1989). The studies on HSP90 have shown that the expression of HSP90 $\beta$ is inducible and can be regulated by all kinds of environmental stresses, such as heat shock (Farcy et al., 2007; Jiang et al., 2009), bacterial challenge (Wei et al., 2013), and heavy metals (Ivanina et al., 2009).

Aquatic animals are usually subjected to a variety of environmental stresses, such as thermal shock, bacteria, virus, and oxygen. Therefore, aquatic animals need to develop an effective and helpful system to adapt to adverse environments. Increasing evidence has suggested that the pivotal role of HSP90 proteins to control multiple-target pathways allows them to link to a wide range of cellular processes such as hormone signaling, cell cycle control, cell proliferation, cell differentiation, apoptosis, tumorigenesis, immune response, and stress defense (Csermely et al., 1998; Helmbrecht et al., 2000; Tsutsumi and Neckers, 2007). As an important member of the HSP family, HSP90 has recently received considerable attention in aquaculture research. To date, several HSP90s have been reported, and the expression level of the HSP90 gene has been investigated in fish species, such as miiuy croaker (Wei et al., 2013), mountain minnow (Liu et al., 2012), carp (Hermesz et al., 2001), senegalese sole (Manchado et al., 2008), and rainbow trout (Cara et al., 2005). However, investigations on the response of HSP90 gene at the functional level in teleost fish are lacking. 
Megalobrama amblycephala is considered to be a principal species in Chinese freshwater polyculture systems, with enormous total annual production (Sun et al., 2014). Studies have revealed that fish in polyculture systems were often at a high risk of being subjected to excessive nitrite concentrations, which can cause various physiological disturbances. However, the stress responses of M. amblycephala HSP90 against nitrite stress are largely unknown. The main objectives of the present study are to 1) clone the cDNA of M. amblycephala HSP90 (designated MaHSP90), 2) investigate the mRNA expression of HSP90, caspase-8, and caspase-9 in the gills of M. amblycephala under nitrite stress, 3) analyze the response of MaHSP90 under nitrite stress by using Western blot analysis, and 4) investigate histological changes in the gills to identify the extent of oxidative stress caused by acute nitrite toxicity.

\section{MATERIAL AND METHODS}

\section{Tissue preparation}

M. amblycephala juveniles (average weight, $18.16 \pm 2.54 \mathrm{~g}$ ) were obtained from the Yixing fish farm at the Freshwater Fisheries Research Center, Chinese Academy of Fishery Sciences. Before the experiment, fish were fed a commercial diet for 2 weeks. Adult fish were anesthetized in water containing $100 \mathrm{mg} / \mathrm{L}$ MS-222 (Sigma). Seven tissues (kidney, liver, heart, intestine, gill, muscle, and brain) from M. amblycephala were removed and kept at $-80^{\circ} \mathrm{C}$ until use. In the nitrite stress tests, $M$. amblycephala juveniles were randomly divided into two nitrite treatment groups performed in triplicate: one group was subjected to $0.02 \mathrm{mg}$ nitrite/L (control) and another was treated with $15 \mathrm{mg}$ nitrite/L (55\% 96-h $\mathrm{LC}_{50}$ ); the latter concentration was prepared by adding a stock solution of sodium nitrite according to preliminary studies. Fish in aerated running water served as controls $(0.02 \mathrm{mg}$ nitrite $/ \mathrm{L})$. Water temperature was kept at $25^{\circ} \pm 0.5^{\circ} \mathrm{C}$ by using aquarium heaters, and $\mathrm{pH}$ was maintained at $7.8 \pm 0.1$. Six $400-\mathrm{L}$ tanks were used to rear the fish for each nitrite concentration $(\mathrm{N}=30$ per tank). For each tank, the gills from three individuals were sampled at $0,3,6,12,24$, and $48 \mathrm{~h}$ after nitrite exposure, and then kept at $-80^{\circ} \mathrm{C}$.

\section{RNA extraction and cloning of the MaHSP90 gene}

Total RNA was isolated from the gills by using RNAiso Plus Reagent (TaKaRa) according to the protocol provided by the manufacturer. The isolated RNA was treated with RNase-free DNase I (Sangon, Shanghai, China) to eliminate possible genomic DNA contamination. The RNA concentration and purity were assessed spectrophotometrically by measuring their absorbance at 260 and $280 \mathrm{~nm}$ by using a Biophotometer (Eppendorf, Germany). RNA fragmentation state was evaluated by conducting $1 \%$ agarose metamorphic gel electrophoresis.

The HSP90 cDNA sequence was extended using 5'- and 3'-rapid amplification of cDNA ends (RACE) and a total of four gene-specific primers (Table 1) developed on the basis of a 513-bp fragment of the HSP90 gene (isotig06936) obtained from a de novo transcriptomic library (Gao et al., 2012) of M. amblycephala. An SMART ${ }^{\mathrm{TM}}$ RACE cDNA Amplification Kit (Clontech, USA) was used to perform 5'/3'-RACE by using gill cDNA as a template following the manufacturer protocol. The initial 3'-RACE polymerase chain reaction (PCR) was performed in a total volume of $50 \mu \mathrm{L}$ that contained $2.5 \mu \mathrm{L}$ of the first-strand cDNA as template, $5 \mu \mathrm{L} 10 \mathrm{X}$ Advantage 2 PCR buffer, $1 \mu \mathrm{L} 10 \mathrm{mM}$ dNTPs, $5 \mu \mathrm{L} 10 \mathrm{mM}$ gene-specific primer (MaHSP90 
01 and MaHSP90 02; Table 1), $1 \mu \mathrm{L}$ Universal Primer A Mix (UPM; Clontech), $34.5 \mu \mathrm{L}$ sterile deionized water, and $1 \mu \mathrm{L} 50 \mathrm{X}$ Advantage 2 polymerase mix (Clontech). Diluted products of the first 3'-RACE PCR (1:50 with Tricine-EDTA buffer) served as template for the 3'-nested PCR. With the exception of the template and nested primer (NUP), contents of the nested PCR were identical to those of the initial reaction. For 5'-RACE, UPM and NUP were used as forward primers in the initial and nested PCRs in conjunction with the reverse gene-specific primers MaHSP90 03 and MaHSP90 04, respectively (see Table 1 for sequence). The PCR conditions were those recommended by the manufacturer for the Advantage ${ }^{\mathrm{TM}} 2 \mathrm{PAC}$ kit (Clontech). The PCR fragments were subjected to electrophoresis on a $1 \%$ agarose gel for determining length difference and cloned into the pMD-18T vector (Takara, Japan). After the vector was transformed into the competent cells of Escherichia coli DH5 $\alpha$, recombinant bacteria were identified using blue/white screening and confirmed by PCR. At least three clones were sequenced from both the strands by using an ABI3730XL Automated Sequencer and M13 primers.

\begin{tabular}{lll}
\multicolumn{2}{l}{ Table 1. Sequences of the primers used in this study. } & \\
\hline Primer & Sequence (5'-3') & Sequence information \\
\hline MaHSP90 01 (first) & TCATCAACACCTTCTATTCCAACA & 3'-RACE primer \\
MaHSP90 02 (nested) & CTGACCTCATCAATAACCTGGCAC & 3'-RACE primer \\
MaHSP90 03 (first) & CAGCCTGAAAGCAAAGGTCTCGG & 5'-RACE primer \\
MaHSP90 04 (nested) & AGAGATTTCTCTCCTCAACTGTCA & 5'-RACE primer \\
Clontech ${ }^{\text {TM }}$ Kit primers & & \\
Universal Primer A Mix & CTAATACGACTCACTATAGGGCAAGCAGTGGTATCAACGCAGAGT & 5'-RACE primer \\
& CTAATACGACTCACTATAGGGC & \\
Nested Universal Primer A & AAGCAGTGGTATCAACGCAGAGT & 3'-RACE primer \\
MaHSP90 05 (forward) & TGGTGTGGGATTCTACTC & Real-time primer \\
MaHSP90 06 (reverse) & TGACTGTGAAAGAGCCGC & Real-time primer \\
MaCaspase-8 (forward) & ACGTCTCTGCCTGTTTGGT & Real-time primer \\
MaCaspase-8 (reverse) & ACAGACCTGATCGCACTCC & Real-time primer \\
MaCaspase-9 (forward) & GCGCCCATTCGAGTATGAT & Real-time primer \\
MaCaspase-9 (reverse) & TCCCAAACGAAAAGGCACT & Real-time primer \\
$\beta$-actin (forward) & TCGTCCACCGCAAATGCTTCTA & Real-time primer \\
$\beta$-actin (reverse) & CCGTCACCTTCACCGTTCCAGT & Real-time primer \\
\hline
\end{tabular}

\section{Nucleotide sequence and bioinformatic analyses}

The 5'- and 3'-sequences from RACE were assembled using the partial cDNA sequence corresponding to each fragmental sequence by using DNAMAN 5.0. Sequences were analyzed on the basis of the nucleotide and protein databases by using the BLASTX and BLASTN programs (http://www.ncbi.nlm.nih.gov/BLAST/). The protein prediction was performed using the ORF Finder tool (http://www.ncbi.nlm.nih.gov/gorf/gorf.html). Alignment of multiple sequences was performed using the CLUSTALW program at the European Bioinformatics Institute (http://www. ebi.ac.uk/clustalw/). The SMART program (http://smart.emblheidelberg.de/) and the PROSITE program (http://kr.expasy.org/prosite/) were used to predict the functional sites or domains in the amino acid sequence. Phylogenetic tree analyses were conducted according to the amino acid sequences of the selected HSP90s by using CLUSTAL X1.83 and MEGA 4.0 (Tamura et al., 2007).

\section{MaHSP90 expression in tissues}

The expressions of MaHSP90 mRNA in the kidney, liver, heart, intestine, gill, muscle, and brain were separately detected using quantitative reverse transcriptase-PCR (qRT-PCR). 
All tissues were thoroughly rinsed with the phosphate-buffered saline to remove hemocytes. Total RNA was isolated from different tissues by using RNAiso Plus Reagent (TaKaRa) according to the manufacturer protocol. The first-strand cDNA was synthesized on the basis of PrimeScript RT Reagent Usage information (TaKaRa) by using total RNA treated with DNase I (TaKaRa) as template. cDNA mix was diluted to 1:10 with Milli-Q water (Toyobo, Japan) and stored at $-80^{\circ} \mathrm{C}$ for subsequent qRT-PCR. A 468-bp fragment of the caspase-9 gene and a 1167-bp fragment of caspase- 8 were obtained from a de novo transcriptomic library of $M$. amblycephala (Gao et al., 2012). Gene-specific primers (Table 1) were used to amplify the HSP90 transcript, and the PCR products were sequenced to verify the specificity of the PCR primers. The $\beta$-actin primers were used to amplify the $\beta$-actin fragments that were used as an internal control. The PCR temperature profile and reaction conditions were specified by the manufacturer of SYBR Premix Ex Taq (TaKaRa, Dalian, China) on a 7300 real-time PCR system (Applied Biosystems, USA). On a 96-well plate, each sample was run in triplicates along with the internal control gene. Dissociation curve analysis of amplification products was performed at the end of each PCR to confirm that only one PCR product was amplified and detected. After the PCR program, data were analyzed using the ABI 7300 SDS software (Applied Biosystems). Consistency was maintained by automatically setting the baseline by the software. The $2^{-\Delta \Delta \mathrm{Ct}}$ method was used for analyzing the relative expression level of MaHSP90 (Livak and Schmittgen, 2001).

\section{MaHSP90 expression in response to nitrite exposure}

In the nitrite-exposure treatments, gill tissues collected at $0,3,6,12,24$, and $48 \mathrm{~h}$ in each replicate were preserved in liquid nitrogen for the RNA extraction. mRNA expressions of HSP90 in the gills were measured using qRT-PCR. The gene-specific primers, $\beta$-actin primers, and PCR conditions were the same as those described above.

\section{Sodium dodecyl sulfate-polyacrylamide gel electrophoresis (SDS-PAGE) and Western blot}

The equivalent of $25 \mu \mathrm{g}$ total lysates for each sample was separated on $7.5 \%$ SDSPAGE under reducing conditions according to the method of Laemmli (1970). The SDS-PA minigels were transferred to a nitrocellulose membrane by using a semidry transfer apparatus (BioRad) and blocked with 5\% bovine serum albumin (BSA) in TBS-T [20 mM Trizma base, $\mathrm{pH} 7.5 ; 300 \mathrm{mM} \mathrm{NaCl}, 0.1 \%$ (v/v) Tween 20 with $0.02 \%$ sodium azide] for $1 \mathrm{~h}$ at room temperature. According to previous reports (Maricchiolo et al., 2011), commercial antibodies for identifying fish HSPs were used as described below. The membranes were incubated overnight with anti-mouse HSP90 monoclonal antibodies (1:3000 dilution, $1 \mathrm{~h}$ at room temperature at $4^{\circ} \mathrm{C}$ ) from Sigma-Aldrich, washed with TBS-T (three times for $5 \mathrm{~min}$ ), and incubated with alkaline phosphatase-conjugated goat anti-mouse $\operatorname{IgG}(1: 10,000$ for $1 \mathrm{~h}$ at room temperature. After the membranes were washed with TBS-T (three times for $5 \mathrm{~min}$ ), they were incubated with 5-bromo-4-chloro-3-indolyl phosphate/nitro blue tetrazolium liquid substrate system (BCIP/NBT). Densitometric analysis of the immunoblotted bands was performed using the AlphaImager software. Control and nitrite treatment groups were examined at $0,6,12$, 24 , and $48 \mathrm{~h}$. Each assay was repeated three times. 


\section{Histopathology}

Fish from the nitrite-exposed group were anesthetized with an overdose of MS-222 to determine the histopathological effects of acute nitrite exposure on fish gills at $0,12,24$, and $48 \mathrm{~h}$. Gills were removed and preserved in 10\% neutral-buffered formalin for $48 \mathrm{~h}$. They were rinsed in $70 \%$ ethanol and stored until further processing. The gills were dehydrated in isopropanol, cleared in xylene, infiltrated in paraffin, and then sectioned at a thickness of $5 \mu \mathrm{m}$. Sections were stained with hematoxylin and eosin and examined using a light microscope (Nikon Phase Contrast 0.90 Dry, Japan). Gill tissue morphology was assessed in order to observe the possible alterations revealed through differences in the condition of gill cell morphology.

\section{Statistical analysis}

All data were provided in terms of relative mRNA reported as means $\pm \mathrm{SE}(\mathrm{N}=3)$. Further, the data of fold-change of expression were logarithmic transformed before subjected to one-way analysis of variance (one-way ANOVA) by using SPSS 14.0. When the overall differences were significant, the Tukey test was used to determine differences among the treatments. Differences were considered to be statistically significant at $\mathrm{P}<0.05$.

\section{RESULTS}

\section{Characteristics of the MaHSP90 gene}

The cDNA sequence of MaHSP90 was deposited in GenBank under accession No. KF195932. The full length of M. amblycephala HSP90 cDNA was 2674 bp and consisted of a 5'-terminal untranslated region of $87 \mathrm{bp}$ and a 3'-terminal untranslated region of $334 \mathrm{bp}$ with a canonical polyadenylation signal sequence ATTAAA. The open reading frame was $2250 \mathrm{bp}$ that encoded a 750-amino acid long protein with a predicted molecular mass of 86.17 $\mathrm{kDa}$ and theoretical isoelectric point of 4.95 . Five conserved HSP90 family signatures were identified in the deduced amino acid sequence of MaHSP90: signature 1, NKEIFLRELISNAS DALDKIR; signature 2, LGTIAKSGT; signature 3, IGQFGVGFYSAYLVAE; signature 4, IKLYVRRVFI; and signature 5, GVVDSEDLPLNISRE (Figure 1). The glutamine-rich sequence (QTQDQ) was not found at the N-terminus of MaHSP90. However, the conserved motif "GxxGxG" and C-terminal-conserved MEEVD motif were determined in MaHSP90. These motifs are ubiquitous in all HSP90 family members.

\section{Bioinformatic analysis of MaHSP90}

The alignment of HSP90 proteins from multiple sources showed that it is highly conserved within fish (Figure 2). The amino acid sequence identity of MaHSP90 ranges from 91.42\% (Oncorhynchus mykiss) to 98.35\% (Gobiocypris rarus) with other known fish HSP90 $\beta$ isoform homologues (Table 2). On the basis of the sequences of HSP90s, we constructed a phylogenetic tree by using CLUSTAL X 1.83 and MEGA 4.0 (Figure 3). The relationships revealed by the phylogenic tree were generally in agreement with the concept of traditional taxonomy. 
A 1 88 at gcctg aag aastgogccaagatgaggaggccg agacetttgcettccaggcagagattgcceagctgatgtc $M$ M E E M $R$ Q D D E E A A E I F A F 163 ct cat tat caacacet tet act ccaacaaagagat ct cet cagggagct cat ctccaacgectct gat gct ctt L I I N 238 gacaaaat cazgt atgaaagttt gac azatcccaccaaact gzacagt gzcaaggacet gaagatcgacatt at $\begin{array}{lllllllllllllllllllllll}D & K & I & R & Y & E & S & L & T & D & P & I & K & L & D & S & G & K & D & L & K & I & D\end{array}$ 313 cccaacgttcatgaacgcactct taccattattgacaccggtattggaat gaccaaagccgatct catcaat aac

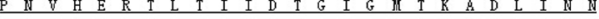

$388 \mathrm{ctgggtaccat}$ cgcaaaģtcczggacaaagzcct tcat ggaggctct gcaggct ggt gcczacatctccat gatt

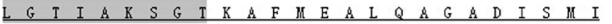

463 gggcagtttggtgtgggattctactccgcct acct ggtggctgaaaaggt cacgztcat cact aaaaacaacgat

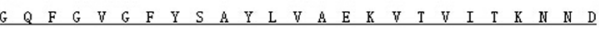
538 gacgagcagt acgcct gggagtcgtccgctggcggctctttcacagtc aaggttgaccat ggtgagcccatt ggc $\begin{array}{lllllllllllllllllllllllll}D & E & Q & Y & A & W & E & S & S & A & G & G & S & F & T & V & K & V & D & H & G & E & P & I & G\end{array}$

$613 \mathrm{cgtggaaccag}$ agtcattct tcacct gaagg aag atcagacagagt acgt cgaggagaagagggtgaaggaagt $\begin{array}{llllllllllllllllllllllllll}R & G & T & R & V & I & L & H & L & K & E & D & B & I & E & Y & V & E & E & K & R & V & K & E & V\end{array}$

688 gtcaagaaacactctcagttcatcgg at accc aat cactctettcgtggag aaggaacg cgacaaggag atcagt $\checkmark$ K K H 763 gacg acg agg cagagg aggagaaagaggagaagg ctgagaaggaggaaagggaggaaggcgaagacaaaccc aag

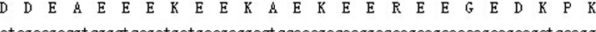

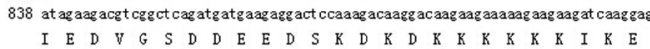
913 aagt acatcgaccazgazzagct gaacaagaccaaacccat ct ggaccogcaaccet gaczacatctccaacgag

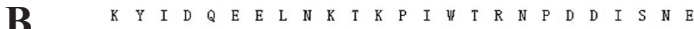
988 gagt acggagagttttacaagagcctgaccaacg att gggaagac cacctggctgtcaagcatttctctgt gga E Y G E F Y K S L I H L A V K H F S V E G Q L E F $1063 g g t c a g c t$ ggagtttcgcgctcttctttt cat ccctegcegcgcococttcgacetctt cgagaacaag aaaaag

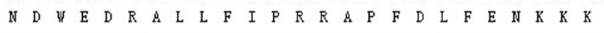
1138 aagaataacat caagct gt acgtcagaagggtct catcat ggacagctgtgaggagct cat cccagggtat ctg $\begin{array}{llllllllllllllllllllllllll}K & \text { II } & \mathbb{N} & \text { I } & K & L & Y & V & R & R & \text { N } & F & I & \text { M } & D & S & C & E & E & L & I & P & G & Y & L\end{array}$ 1213 aact ttat cegtggtgttgtggactctgaagatctgcectcaacat ctccagagag at gctgcaacag agc aag N F I R G V V D S E D L P L N I S R E ML Q Q S K 1288at tct caaggtcatccgcaagaacat cgtcaagaagt gect ggagct gtttgct gagct ggcagaggac aaggaa

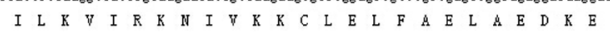

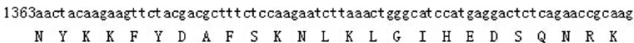
138aagctot cagaact gct gcgtt atcagagctcacastccgrcgacgagatgacctccetcacagaatacotcoge K L S E L L R Y Q S S Q S G D E II T S L T E V V S K L $S$ e L $R$ Y $R$ 1513cgtat gaaggaaacccagaaat caatct att acat cactggtgagag caaagaccaggt cgcccactct gcttt $\begin{array}{llllllllllllllllllllllllll}R & \text { II K } & \text { E } & \text { I } & Q & K & S & I & Y & Y & \text { I } & \text { I } & G & \text { E } & S & K & D & Q & V & A & H & S & \text { A } & F\end{array}$

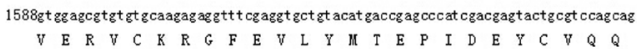

C 1663ctgaaggactttgatggcaagtctct ggtgtccgt caccgaagaggzgct ggagctacct gaggat gaagacgag $\begin{array}{llllllllllllllllllllllllll}L & K & D & F & D & G & K & S & L & V & S & V & T & E & E & G & L & E & L & P & E & D & E & D & E\end{array}$ 1738 aagaaaaagat ggaggaag acaaggccaagtttgagaacct gtgcaagct cat gaaggagattct ggacaagaa $\begin{array}{llllllllllllllllllllllllll}K & K & K & M & E & E & D & K & A & K & F & E & N & L & C & K & L & \text { II } & K & E & I & L & D & K & K\end{array}$ 1813gt agagaaagtcaccgt at caaacaggct ggtttctt ccccet gct gt at cgt gaccagcacttacggctggacg V E K K V T T V S N N R L L V S S P P C C I V T S I Y $\begin{array}{rl}1888 g c c a a c a t & g g a g a g g a t \\ \text { A N }\end{array}$ 963cacct ggagatcaaccccgatcatcccatcat ggagaccct gaggcag aag gct gat gcagat aaaaacgacaa H L E I N P D H P I Y F T L R B K \& D \& D K N D K 2038gccgt gaaggatccggt cgtcctcctgttcgagactgcgctgctttcctct gggttctcattggacgatcctcag

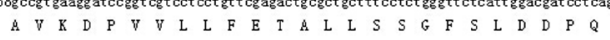
2113 acacact caaaccgtat ct acagaat gat caagct tggat tgggtgtt gat gaagat gaagacgt gcctgtcgaa

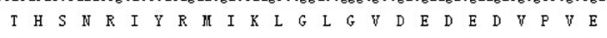
2188gagcc aagctccgctcccgctcctg aag agctccc acctct ggaaggagacgat gacgcctctcgcat ggaggaa

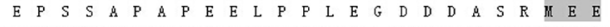
2263gtcgatcaaatccatccgtctct aattccccagtcaattttcogtaat cat tccgt aacatct tat cgttctctc V D Q I H P S L L I P Q S I F R N H S V T $2338 \mathrm{tga}$

234 1cctgt ag aaggttt acctgatct cagtaatgattcct aaagt atcat aat gt gt aact aaagcgt act gt ccac $2416 \mathrm{tttt}$ gct ctgttt gag ccatt atgt act ttt gttttt tacat atgtt cat gg atcaat gggttgctgcggt at 2491 gtct gagcacgat aagcact gt gtttcactgatactg agt ctgctggctgtgctggattgaat caagcatgattt 2566 cattctgcatggaaagg gaaag acctttgcct gag tac aggcttgtgttgttattggttttcagaaatt aaaaca

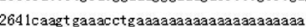

Figure 1. Nucleotide and deduced amino acid sequences of HSP90 from Megalobrama amblycephala. Heat shock protein 90 family signature motifs and consensus sequence MEEVD are highlighted as shaded regions. The ATPbinding domain is underlined. Potential polyadenylation signal sequence is in bold. 
A
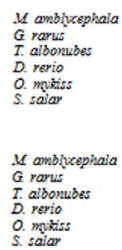

M anbilcephaia

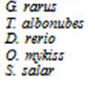

M amblycespha

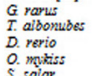

$M$ ambincephata

M ambivephio
G ravus
T. aibonuber
D. rerio D. rerio
O. mikiss
S. salar

B

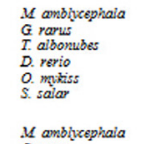

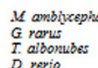

T. arbonibes
O. revio
S. sailar

G anbiycephaia

G rarus albonubes

D. rerio
O. makiss
S. saiar

M ambicephaia

T. albonubes
D. revio
S. mikiss
S. salar

4 ambircephata

G raris
T. albanubes
D. rerio

D. rerio
O. misks
S. saiar

C

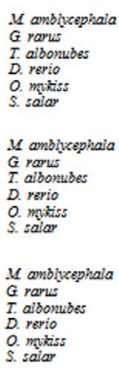

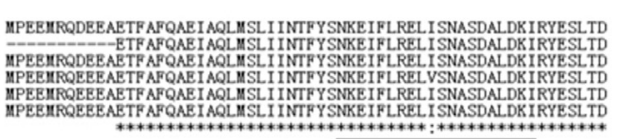

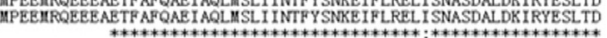

PTKLDSGKDLKIDIIPNVHERTLTIIDTGIGITKADLINNLGTIAKSGTKAPIEALOAGA PTKLDSGXDLXIDII IPNVFDRTLTIIDTGIGITKADLINNLGTIAKSGTKAPIEALAGA

TKLDSGKDLKIDI I PNVQERTLTL IDTG IGITKKADL INNLGTI AKSGTKAFHEALQAGA

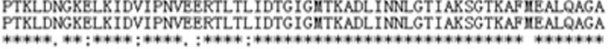

DISMIGQFGVGPYSAYLVAEKVTVITKNNDDEQYAWESSAGGSPTVKVDHGEPIGRGTRV DISHI IGEFGVGFY SAYLVAEKVIVITKNNDDEQYANESSAGGSPTVKVDHGEPIGRGTRV

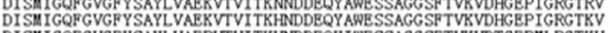
DISMI I QQFGVGFY SAYLVAERVTVITKHNDDEQY I WESSAGGSF TVKVDTGEPILRGTKV DI INI IGQPGVGFYSAYLVAERVTVITKHNDDEQY IWESSAGGSPTVKVDTGEPMLRGTKV

ILHLKEDQTEYVEEKRVKEVVKKHSQF IGYPITLFVEKERDKE I SDDEAEEEKEEKAEKE TLHLKEDQTEYVEEKRVKEVVKHSOF IGYPITLFVEKERDKEI SDDEAEEEKAEKEEKE LLLKKEDQTEY I EEKRVKEVVKKHSQF I GYPITLYVEKERDKE ISDDEAEEEKAEKEEK

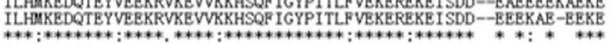
EREEGEDKPKIEDVG SDDEEDSKDKDKKKKKKIKEKYIDQEELNKTKPI ITRNPDDI SNE

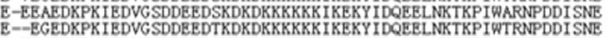

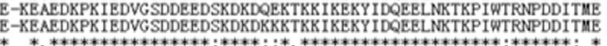

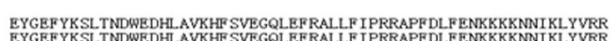
TY

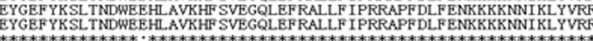
VFIMDSCEELIPGYLNF IRGVVDSEDLPLNISREMLQSKILKVIRKNI VKKCLELFAEL FIMDSCEELIPEYLNF IRGVVDSEDLPLNISREMLQQSKILKVIRKNIVKKCLELFAE

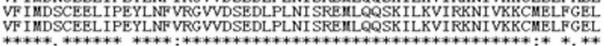
AEDKENYKKFYDAF SKNLKLGI IHEDSQNRKKLLSELLRYQSSQSGDERTSLTEYVSRMKET
AEDKENYKKFYDAF SKNLKLG HEDSQNRKKLSELLRYQSSQSGDEMTSLTEYVSRMKEN AEDKENYKKFFYDAF SKNLKLG I IHED SQNRKKLLSELLRYQSSQSGDEET TSLTEYVSRMKEN

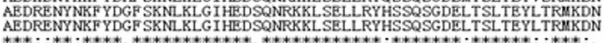
QKSIYYITGESKDQVAHSAFVERVCKRGPEVL YMTEPIDEYCVQQLKDFDGKSLVSVTEE

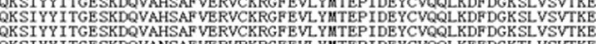

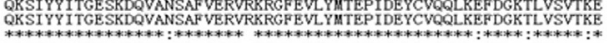

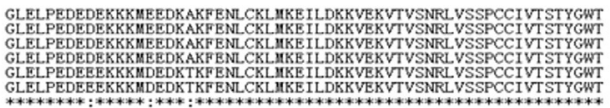

ANMERI MKAOALRDNSTHCYMUAKKHLEINPDHPI IRETLROKADADKNDKAVKDPYVLL

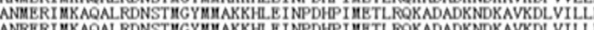

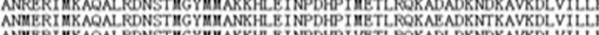

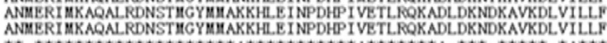

BTALLSSGFSLDDPQTHSNRI YRUI KLGLGGDEDEDVPVEEPSSAPAPEELPPLEGDDDA

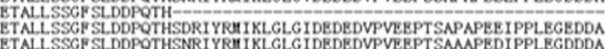

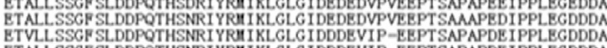
BTVLLSG FSLDDPTHSNRIYRIIKLGLGIDDDEVIP-EETSAPAPDEIPPLEGDDDA
ETALLSSGFSLDPQTHSNRIYRII KL.GLGIDDDEVIP-EEPTSAPAPDEIPPLEGDDA

SRMEEVDQIHPSLIPQSIFRNHSVTSYRSL.

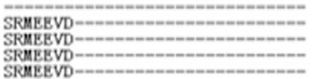

Figure 2. Alignment of Mma manganese superoxide dismutase (MnSOD) with other invertebrate homologues: Megalobrama amblycephala (KF195932), Hypophthalmichthys molitrix (ADM86391.1), Hemibarbus mylodon (ACR23311.1), Danio rerio (NP_956270.1), Sparus aurata (AFV39807.1), and Epinephelus coioides (AAW29024.1). HSP90 family signature sequences and consensus sequence "MEEVD" at the C-terminal are underlined. The symbols (asterisks, colons, and periods) in the ClustalW alignment format represent identical residues, conserved substitutions, and semi-conserved substitutions, respectively. 
Table 2. Matrix indicating the percentage identities of the aligned HSP90.

\begin{tabular}{|c|c|c|c|c|c|c|}
\hline & 1 & 2 & 3 & 4 & 5 & 6 \\
\hline $\begin{array}{l}1 \text { Megalobrama amblycephala } \\
\beta \text { isoform } \\
2 \text { Gobiocypris rarus }\end{array}$ & 100 & - & - & - & - & - \\
\hline $\begin{array}{l}\beta \text { isoform } \\
3 \text { Tanichthys albonubes }\end{array}$ & 98.35 & 100 & - & - & - & - \\
\hline$\beta$ isoform & 97.25 & 98.80 & 100 & - & - & - \\
\hline 4 Danio rerio & 96.14 & 97.44 & 96.41 & 100 & - & - \\
\hline 5 Salmo salar $\beta$ isoform & 91.83 & 92.74 & 91.96 & 91.84 & 100 & - \\
\hline 6 Oncorhynchus mykiss $\beta$ isoform & 91.42 & 92.45 & 91.69 & 91.68 & 98.89 & 100 \\
\hline
\end{tabular}

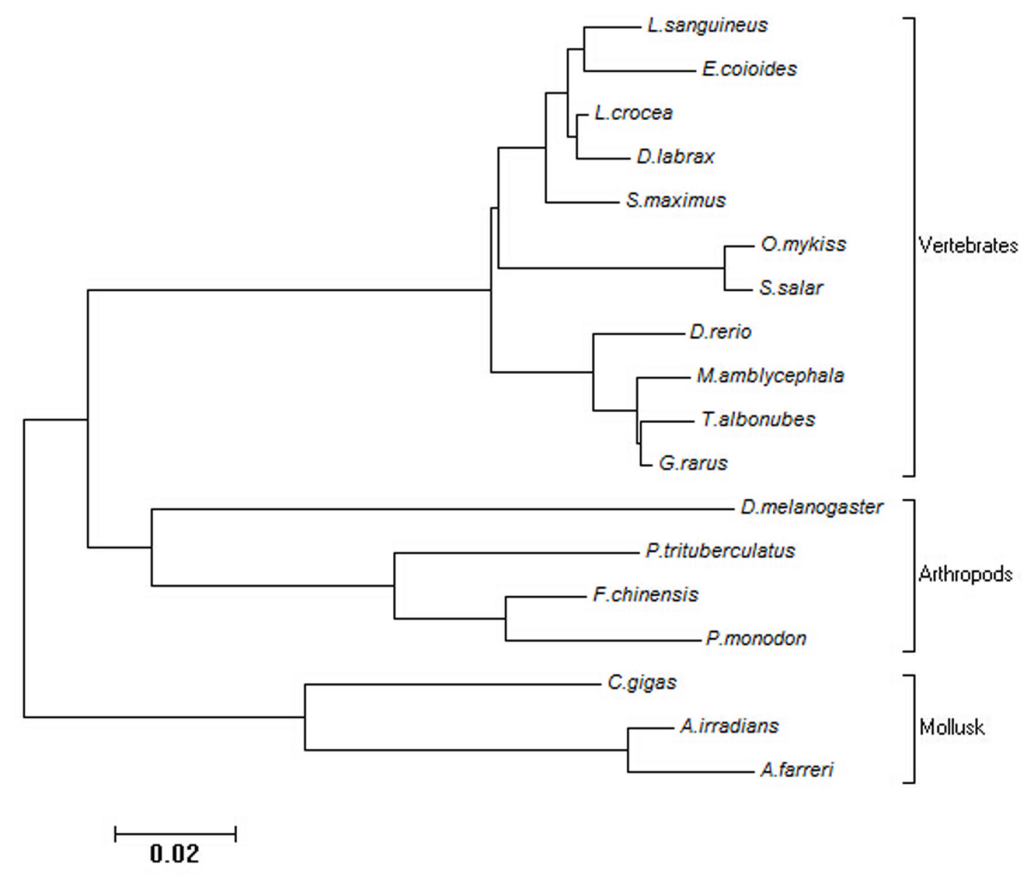

Figure 3. Consensus neighbor-joining tree developed on the basis of the sequences of different types of manganese superoxide dismutase. The numbers at the forks indicate the bootstrap. The detailed information for the used sequences are as follows: Megalobrama amblycephala (KF211478), Tanichthys albonubes (ADK27678.1), Oncorhynchus mykiss (NP_001117703.1),Daniorerio(AAB96969.1), Salmosalar(NP_001117004.1),Fenneropenaeus chinensis (ABM92446), Drosophila melanogaster (CAA27435), Penaeus monodon (ACO83357), Gobiocypris rarus (ADY38799.1), Scophthalmus maximus (ABU50778.1), Dicentrarchus labrax (AAQ95586.1), Lutjanus sanguineus (ADK91577.1), Larimichthys crocea (AEP68104.1), Epinephelus coioides (ACV04938.1), Crassostrea gigas (ABS18268), Argopecten irradians (ABS50431), Chlamys farreri (AAR11781), and Portunus trituberculatus (ACQ90225).

\section{Tissue distribution of MaHSP90 mRNA}

The mRNA expression of MaHSP90 could be detected using qRT-PCR in all tested tissues, including brain, heart, muscle, kidney, gill, intestine, and liver (Figure 4). The highest MaHSP90 expression (18.54-fold) was observed in the brain, followed by that in the liver and heart; the expression levels were comparable among the kidney, gill, muscle, and intestine. 


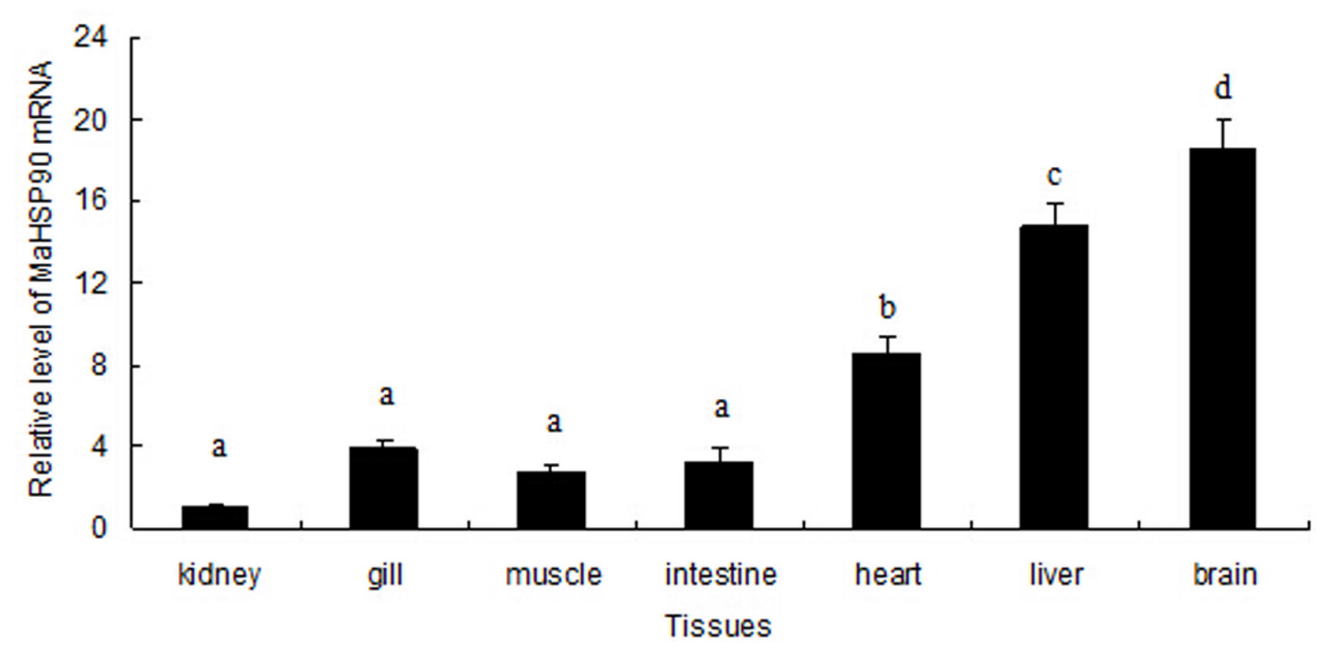

Figure 4. Fold-change of HSP90 gene expression in various tissues (brain, gill, heart, intestine, liver, muscle, and kidney) of Megalobrama amblycephala. HSP90 mRNA levels are reported as a ratio relative to $\beta$-actin levels in the same samples used for performing quantitative real-time-polymerase chain reaction (qRT-PCR). All values are reported as means $\pm \mathrm{SE}(\mathrm{N}=3)$. Bars with different letters indicate significant differences $(\mathrm{P}<0.05$; Tukey test).

\section{Expression of MaHSP90 mRNA and protein after nitrite stress}

The temporal expression of MaHSP90 in the gills increased after nitrite stress (Figure 5A). Expression levels were up-regulated at $3 \mathrm{~h}$ post-exposure $(\mathrm{P}<0.05)$, reached peak values at $12 \mathrm{~h}(\mathrm{P}<0.05)$, decreased at $24 \mathrm{~h}$ post-exposure, and finally, recovered to the baseline levels at 48 and $72 \mathrm{~h}$. The HSP90 protein production was assessed by performing densitometry analysis of the immunoblotted bands. Analysis results of gill samples from control and treatment groups led to the identification of specific anti-mouse HSP90 (Figure 5B). The densitometry profile (Figure 5C) showed no changes in the control samples. Under nitrite stress, there was significant increase in the band density values from 6 to $12 \mathrm{~h}$. On the other hand, the relative expression levels of caspase- 8 and caspase-9 mRNA from the gills of $M$. amblycephala subjected to nitrite exposure were both up-regulated at $24 \mathrm{~h}$ post-exposure (Figure 6). The caspase- 8 and caspase- 9 mRNA expression levels were up-regulated at $24 \mathrm{~h}$ post-exposure $(\mathrm{P}<0.05)$ and reached peak at $48 \mathrm{~h}(\mathrm{P}<0.05)$. From 0 to $12 \mathrm{~h}$ post-exposure, the amount of caspase- 8 and caspase- 9 transcripts remained stable.

\section{Histological changes}

Histological sections of gills from control fish showed no abnormality (Figure 7A). The histological sections of gills from fish treated with $15 \mathrm{mg}$ nitrite/L revealed increases in epithelium interstitial edema, epithelial hyperplasia, and lamellar aneurisms after 12 and $24 \mathrm{~h}$ (Figure 7B and C). Gill lamellar destruction and lamella fusion were noted after $48 \mathrm{~h}$ of nitrite exposure (Figure 7D). 


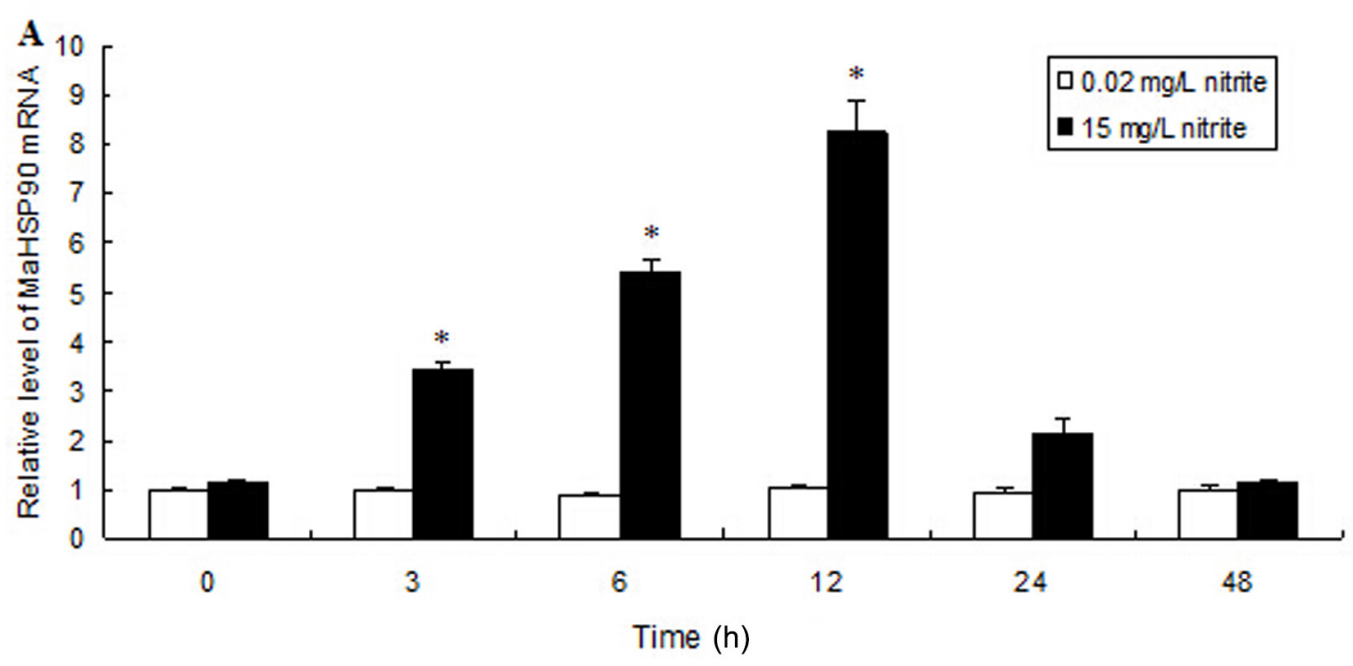

\section{B}

\section{HSP90}
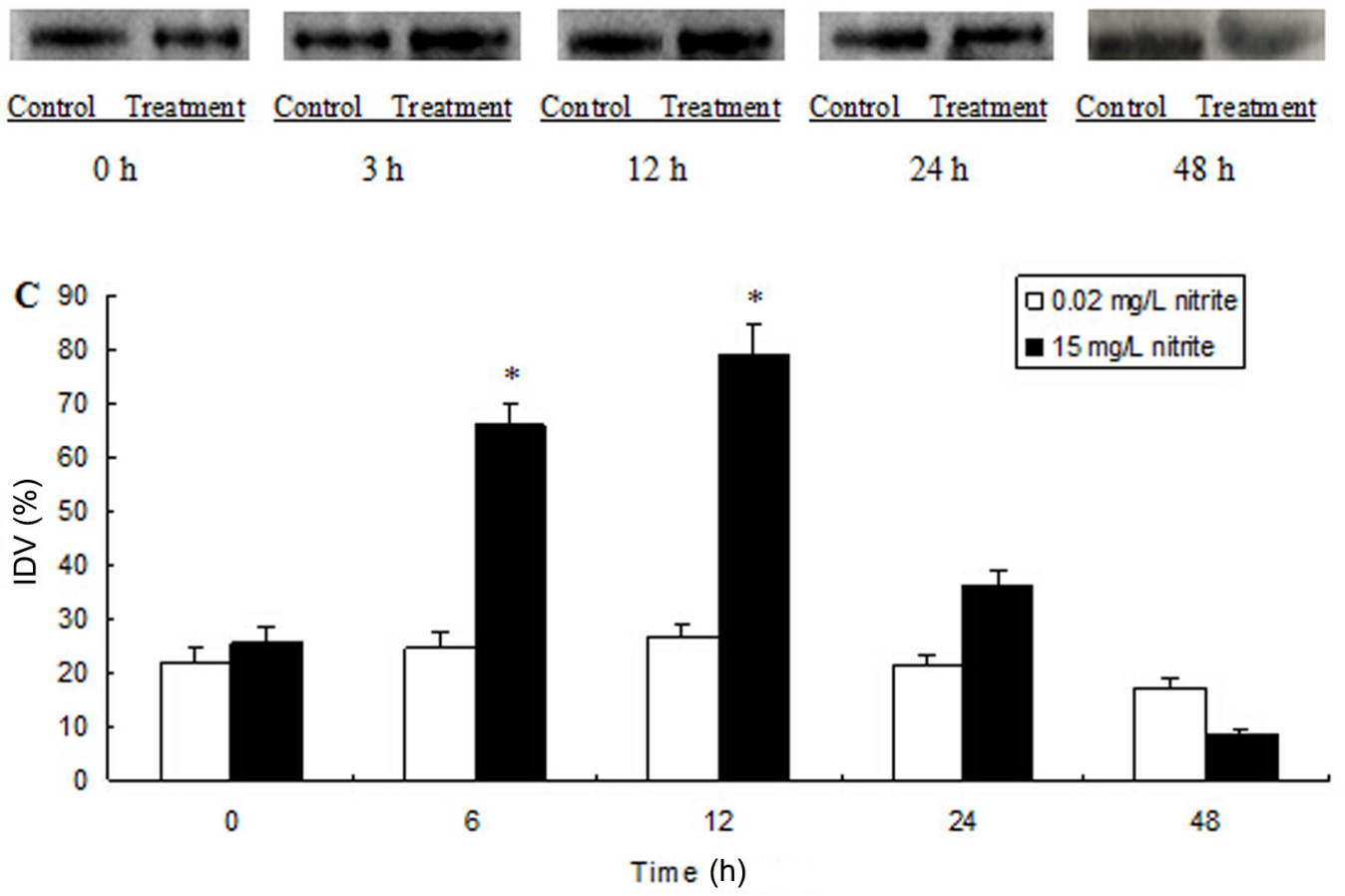

Figure 5. A. Fold-change of HSP90 gene expression in the gills of Megalobrama amblycephala subjected to nitrite compared to that in the control at the same time points $(0,3,6,12,24$, and $48 \mathrm{~h})$ as normalized with the $\beta$-actin gene detected using the $t$-test. B. Representative Western blot of HSP90. C. Integrated optical density histogram (IDV) of the HSP90 protein bands. Values are reported as mean $\pm \mathrm{SE}(\mathrm{N}=3)$. Asterisks indicate significant differences $(\mathrm{P}<0.05)$. 

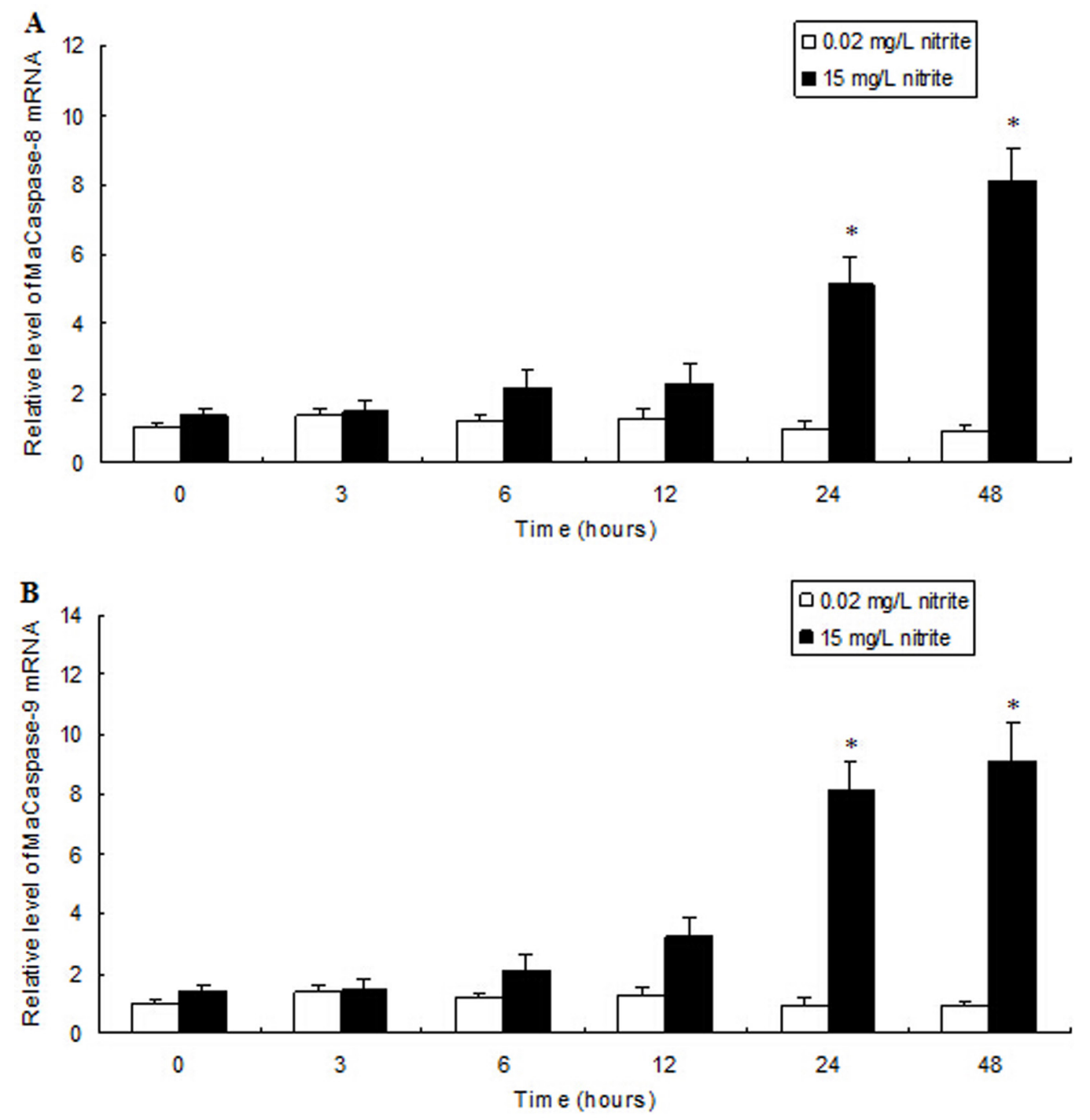

Figure 6. Fold-changes in mRNA expression of caspase-8 (A) and caspase-9 (B) in the gills of Megalobrama amblycephala juveniles. Differences between groups exposed to nitrite and the controls were assessed by performing $t$-tests at each time points $(0,3,6,12,24$, and $48 \mathrm{~h})$ after normalization to $\beta$-actin expression. Values are reported as means $\pm \mathrm{SE}(\mathrm{N}=3)$. Asterisks indicate significant differences $(\mathrm{P}<0.05)$.

\section{DISCUSSION}

The main toxic action of nitrite on aquatic animals is due to the conversion of oxygencarrying pigments to forms that are incapable of carrying oxygen, which causes hypoxia and ultimately death (Camargo and Alonso, 2006). Mass mortality in M. amblycephala has often been associated with nitrite stress. HSP90, a member of the stress-related protein family, 

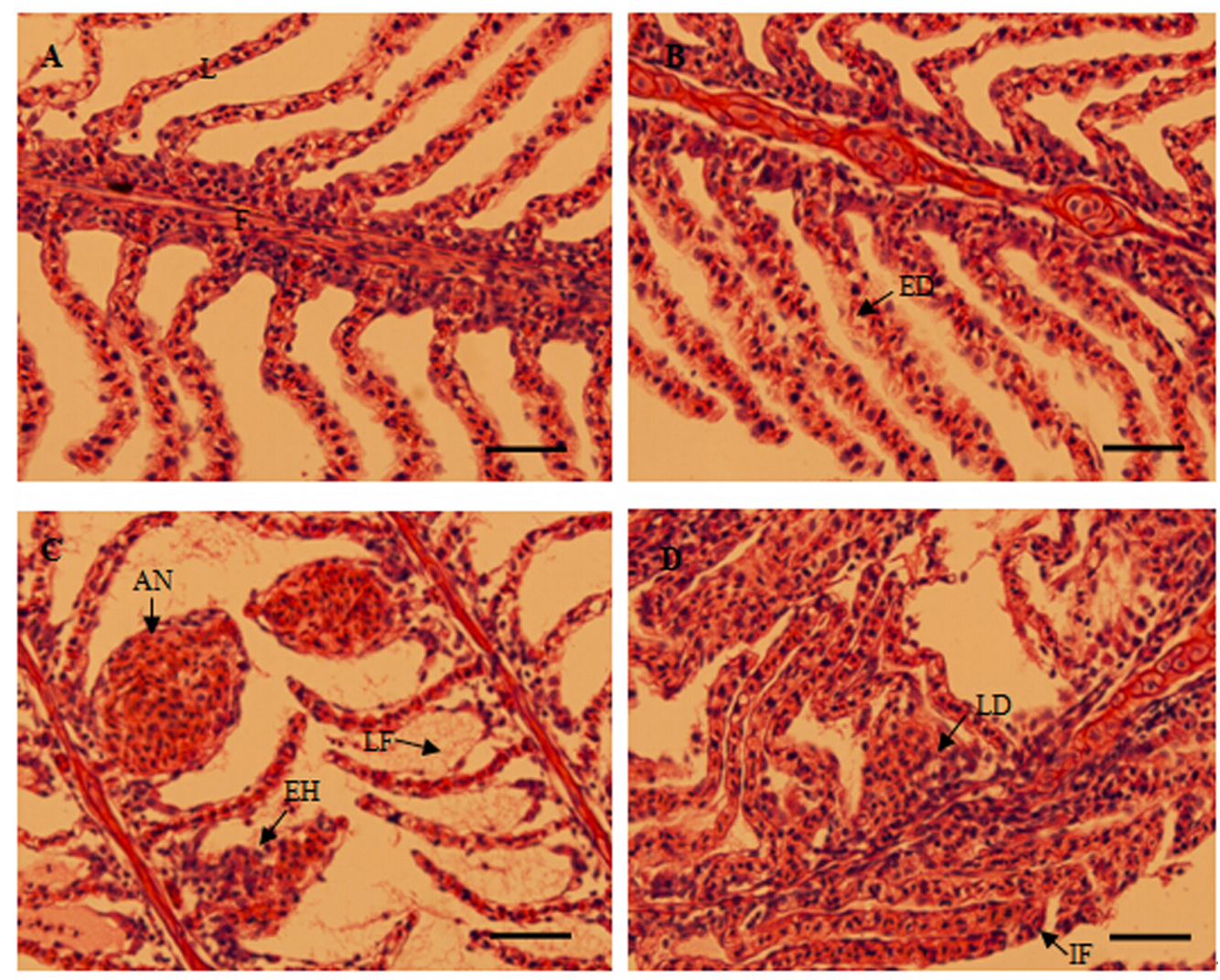

Figure 7. Histological sections of gills stained with hematoxylin and eosin from Megalobrama amblycephala juveniles treated with $15 \mathrm{mg}$ nitrite/L at $0 \mathrm{~h}$ (control gill, $\mathbf{A}), 12 \mathrm{~h}(\mathbf{B}), 24 \mathrm{~h}(\mathbf{C})$, and $48 \mathrm{~h}(\mathbf{D}) . \mathrm{F}=$ filaments; $\mathrm{L}=$ lamellae; $\mathrm{ED}=$ epithelium interstitial edema; $\mathrm{AN}=$ lamellar aneurisms; $\mathrm{EH}=$ epithelial hyperplasia; $\mathrm{LD}=$ lamellar destruction; IF = lamella fusion. Scale bar $=50 \mu \mathrm{m}$.

plays an important role in defending cells against external stressors, such as changes in heavy metal exposure and pathogen invasion. Therefore, cloning the full-length cDNA of HSP90 and analysis of its expression profiles in gills under extreme nitrite exposure might contribute to the development of strategies for the mass control of aquaculture mortality.

In the present study, the complete cDNA sequence of the HSP90 gene was cloned and characterized from the gills of M. amblycephala. Sequence alignment analysis showed that MaHSP90 contains five well-conserved family signature motifs and one ATP-binding domain, which is essential for the basic function of HSP90 (Prodromou et al., 1997; Hartl and HayerHartl, 2002). In addition, there are two cytosolic isoforms of the HSP90 gene (HSP90 $\alpha$ and HSP90 $\beta$ ) in vertebrates, which differ in the structure of the glytamine-rich sequence (QTQDQ) at the N-terminus (Lees-Miller and Anderson, 1989). In general, the QTQDQ sequence is not found in the amino acid sequence of HSP90 $\beta$ isoform. In this study, the QTQDQ sequence was not found in the MaHSP90 N-terminus, suggesting that MaHSP90 was similar to the vertebrate HSP90 $\beta$ isoforms. Homology analysis suggested that MaHSP90 shared 91.42-98.35\% with HSP90 $\beta$ isoforms of other known species. Especially, there was $98.35 \%$ similarity in the 
amino acid sequence of the HSP90 $\beta$ isoform between M. amblycephala and G. rarus. The results of multiple alignments, structural analysis, and phylogenetic tree analysis also suggest that MaHSP90 should belong to the HSP90 $\beta$ isoform family. qRT-PCR analysis indicated that mRNA expression of MaHSP90 could be detected in all tested tissues, indicating the constitutive expression of the HSP90 gene. The specific expression of MaHSP90 in different tissues might be due to the difference in protein synthesis in tissues. The expression of MaHSP90 mRNA was the highest in the brain, followed by that in the liver and heart; the lowest level of expression was noted in the kidney. High expression of MaHSP90 in the liver is consistent with the findings of previous studies on Miichthys miiuy (Wei et al., 2013).

Heat shock proteins are often used as biomarkers in environmental toxicology (Ryan and Hightower, 1996), and HSP90 has been considered as a useful biomarker to assess the nutritional stress in early life stages of fish and as a defense mechanism against a great diversity of stressors such as heat shock, infections, or starvation (Cara et al., 2005; Manchado et al., 2008; Li et al., 2012). The possible biological function of MaHSP90 under stress response was further understood by investigating mRNA expression at different time points after acute nitrite exposure. Previous studies have reported that HSP90 was inducible by a range of stressors (Palmisano et al., 1999; Wu et al., 2012). In the present study, we studied the expression patterns in gills because they are one of the mucosal barriers and play an important role in mucosal immune response (Cui et al., 2014). M. amblycephala subjected to nitrite treatment showed significant changes in the expression of the HSP90 gene in the gill tissues; similarly, HSP90 protein expression was higher in the gills as revealed by the immunoblotting analysis performed using anti-mouse HSP90 monoclonal antibodies. These results indicated that MaHSP90 expression was induced under and played a key role in response to nitrite stress.

Nitrite, the principal end-product of protein catabolism, is one of the important environmental toxic factors in ponds. At present, how nitrite promotes HSP90 expression in $M$. amblycephala gill tissue is not known, but two mechanisms seem plausible. First, a previous study reported that the imbalance between reactive oxygen species (ROS) and antioxidant defenses is one mechanism underlying nitrite toxicity in M. amblycephala (Sun et al., 2014). In vertebrates, the generation of excess ROS could also lead to protein denaturation or proteotoxicity in the host cells. Thus, increased expression of HSP90, a molecular chaperone, would be triggered by the accumulation of denatured proteins, thereby preventing the formation of additional denatured proteins in the host cells (Ramaglia et al., 2004). Second, oxidative stress is an important factor for inducing apoptosis in various cells (Orrenius, 2007); due to their cytoprotective role, HSPs inhibit key steps in the apoptotic cascade and maintain the physiological homeostasis of the cells. This is possible since apoptosis has been shown to trigger the induction of HSP90 (Sreedhar and Csermely, 2004; Islam et al., 2013). These facts suggest that HSP90 is a gene that is sensitive to nitrite stress and participates in the regulation of the adaptive responses, similar to its role in responses to other environmental stresses.

Elevated nitrite is very toxic to aquatic animals and has a deleterious effect on organisms; gills encompass not just the largest surface area in direct contact with dissolved toxicants but also represent the designated organ for ion and oxygen uptake since they are constantly exposed to water. Consequently, gills are particularly vulnerable to toxicants, and gill morphology has been established as a biomarker for nitrite stressors (Gisbert et al., 2004; Kroupova et al., 2008; Romano and Zeng, 2009). In the present study, exposure to nitrite was shown to cause severe cytological damage to the gill cells, which was consistent with the findings of an earlier study that reported histopathological changes after exposure to nitrite in the gills of the African 
catfish, Clarias lazera (Michael et al., 1987). Some of the histological changes noted in the gills of $M$. amblycephala, such as hypertrophy, hyperplasia, lamellar destruction, and lamella fusion, might be attributed to the morphological features of apoptosis. In this study, HSP90 and caspase- 8 and caspase- 9 mRNA showed distinct expression patterns, suggesting that the specific role of HSP90 in M. amblycephala is associated with apoptosis under acute nitrite exposure.

In conclusion, we cloned and characterized HSP90 $\beta$, an important member of the HSP family, from M. amblycephala. The mRNA expression patterns of HSP90, caspase- 8 , and caspase-9 and associated changes in gill histology under nitrite stress were described for the first time in M. amblycephala. Our findings might form the bases for further studies on protein purification and expression to elucidate the function of HSP90 in M. amblycephala.

\section{ACKNOWLEDGMENTS}

Research supported by the Freshwater Fisheries Research Center of the Chinese Academy of Fishery Sciences, the China Central Governmental Research Institutional Basic Special Research Project from Public Welfare Fund (\#2013A08XK01, \#2013JBFR06), the Modern Agriculture Industrial Technology System Special Project - the National Staple Freshwater Fish Industrial Technology System (Nycytx-46), and the National "Twelfth FiveYear" Plan for Science \& Technology Support (\#2012BAD25B07).

\section{REFERENCES}

Camargo JA and Alonso A (2006). Ecological and toxicological effects of inorganic nitrogen pollution in aquatic ecosystems: a global assessment. Environ. Int. 32: 831-849.

Cara JB, Aluru N, Moyano FJ and Vijayan MM (2005). Food-deprivation induces HSP70 and HSP90 protein expression in larval gilthead sea bream and rainbow trout. Comp. Biochem. Physiol. B Biochem. Mol. Biol. 142: 426-431.

Csermely P, Schnaider T, Soti C, Prohaszka Z, et al. (1998). The 90-kDa molecular chaperone family: structure, function, and clinical applications. A comprehensive review. Pharmacol. Ther. 79: 129-168.

Cui J, Liu SK, Zhang B, Wang H, et al. (2014). Transciptome analysis of the gill and swimbladder of Takifugu rubripes by RNA-Seq. PLoS One 9: e85505.

Farcy E, Serpentini A, Fiévet B and Lebel JM (2007). Identification of cDNAs encoding HSP70 and HSP90 in the abalone Haliotis tuberculata: transcriptional induction in response to thermal in hemocyte primary culture. Comp. Biochem. Physiol. B Biochem. Mol. Biol. 146: 540-550.

Fu D, Chen J, Zhang Y and Yu Z (2011). Cloning and expression of a heat shock protein (HSP) 90 gene in the haemocytes of Crassostrea hongkongensis under osmotic stress and bacterial challenge. Fish. Shellfish Immunol. 31: 118-125.

Gao Z, Luo W, Liu H, Zeng C, et al. (2012). Transcriptome analysis and SSR/SNP markers information of the blunt snout bream (Megalobrama amblycephala). PLoS One 7: e42637.

Gething MJ and Sambrook J (1992). Protein folding in the cell. Nature 355: 33-45.

Gisbert E, Rodríguez A, Cardona L, Huertas M, et al. (2004). Recovery of Siberian sturgeon yearlings after an acute exposure to environmental nitrite: changes in the plasmatic ionic balance, $\mathrm{Na}^{+}-\mathrm{K}^{+} \mathrm{ATPase}$ activity, and gill histology. Aquaculture 239: 141-154.

Hartl FU and Hayer-Hartl M (2002). Molecular chaperones in the cytosol: from nascent chain to folded protein. Science 295: 1852-1858.

Helmbrecht K, Zeise E and Rensing L (2000). Chaperones in cell cycle regulation and mitogenic signal transduction: a review. Cell Prolif. 33: 341-365.

Hermesz E, Ábrahám M and Nemcsók J (2001). Identification of two hsp90 genes in carp. Comp. Biochem. Physiol. C Toxicol. Pharmacol. 129: 397-407.

Islam A, Lv YJ, Abdelnasir A, Rehana B, et al. (2013). The role of Hsp90 $\alpha$ in heat-induced apoptosis and cell damage in primary myocardial cell cultures of neonatal rats. Genet. Mol. Res. 12: 6080-6091.

Ivanina AV, Taylor C, Sokolova IM (2009). Effects of elevated temperature and cadmium exposure on stress protein response in eastern oysters Crassostrea virginica (Gmelin). Aquat. Toxicol. 91: 245-254. 
Jiang S, Qiu L, Zhou F, Huang J, et al. (2009). Molecular cloning and expression analysis of a heat shock protein (Hsp90) gene from black tiger shrimp (Penaeus monodon). Mol. Biol. Rep. 36: 127-134.

Kroupova H, Machova J, Piackova V, Blahova J, et al. (2008). Effects of subchronic nitrite exposure on rainbow trout (Oncorhynchus mykiss). Ecotoxicol. Environ. Saf. 71: 813-820.

Laemmli UK (1970). Cleavage of structural proteins during the assembly of the head of bacteriophage T4. Nature 227: 680-685.

Lees-Miller SP and Anderson CW (1989). The human double-stranded DNA-activated protein kinase phosphorylates the 90-kDa heat-shock protein, hsp90 alpha at two $\mathrm{NH}_{2}$-terminal threonine residues. J. Biol. Chem. 264: 17275-17280.

Li J, Han J, Chen P, Chang Z, et al. (2012). Cloning of a heat shock protein 90 (HSP90) gene and expression analysis in the ridgetail white prawn Exopalaemon carinicauda. Fish. Shellfish Immunol. 32: 1191-1197.

Lindquist S and Craig EA (1988). The heat-shock proteins. Annu. Rev. Genet. 22: 631-677.

Liu H, Chen H, Jing J and Ma X (2012). Cloning and characterization of the HSP90 beta gene from Tanichthys albonubes Lin (Cypinidae): effect of copper and cadmium exposure. Fish. Physiol. Biochem. 38: 745-756.

Livak KJ and Schmittgen TD (2001). Analysis of relative gene expression data using real-time quantitative PCR and the $2^{-\triangle \Delta \mathrm{Ct}}$ method. Methods 25: 402-408.

Manchado M, Salas-Leiton E, Infante C, Ponce M, et al. (2008). Molecular characterization, gene expression and transcriptional regulation of cytosolic HSP90 genes in the flatfish senegalese sole (Solea senegalensis Kaup). Gene 416: 77-84.

Maricchiolo G, Mirto S, Caruso G, Caruso T, et al. (2011). Welfare status of cage farmed European sea bass (Dicentrarchus labrax): a comparison between submerged and surface cages. Aquaculture 314: 173-181.

Michael MI, Hilmy AM, el-Domiaty NA and Wershana K (1987). Serum transaminases activity and histopathological changes in Clarias lazera chronically exposed to nitrite. Comp. Biochem. Physiol. C 86: 255-262.

Orrenius S (2007). Reactive oxygen species in mitochondria-mediated cell death. Drug Metab. Rev. 39: 443-455.

Palmisano AN, Winton JR and Dickhoff WW (1999). Sequence features and phylogenetic analysis of the stress protein hsp90 alpha in chinook salmon (Oncorhynchus tshawytscha), a poikilothermic vertebrate. Biochem. Biophys. Res. Commun. 258: 784-791.

Pearl LH and Prodromou C (2006). Structure and mechanism of the Hsp90 molecular chaperone machinery. Ann. Rev. Biochem. 75: 271-294.

Pratt WB and Toft DO (2003). Regulation of signaling protein function and trafficking by the hsp90/hsp70-based chaperone machinery. Exp. Biol. Med. 228: 111-133.

Prodromou C, Roe SM, O'Brien R, Ladbury JE, et al. (1997). Identification and structural characterization of the ATP/ ADP-binding site in the Hsp90 molecular chaperone. Cell 90: 65-75.

Ramaglia V, Harapa GM, White N and Buck LT (2004). Bacterial infection and tissue specific Hsp72, -73 and -90 expression in western painted turtles. Comp. Biochem. Physiol. C Toxicol. Pharmacol. 138: 139-148.

Romano N and Zeng C (2009). Subchronic exposure to nitrite, potassium and their combination on survival, growth, total haemocyte count and gill structure of juvenile blue swimmer crabs, Portunus pelagicus. Ecotoxicol. Environ. Saf. 72: 1287-1295.

Ryan JA and Hightower LE (1996). Stress proteins as molecular biomarkers for environmental toxicology. Stressinducible cellular responses. EXS 77: 411-424.

Sreedhar AS, Kalmar E, Csermely P and Shen YF (2004). Hsp90 isoforms: functions, expression and clinical importance. FEBS Lett. 562: 11-15.

Sreedhar AS and Csermely P (2004). Heat shock proteins in the regulation of apoptosis: new strategies in tumor therapy, a comprehensive review. Pharmacol. Ther. 101: 227-257.

Sun S, Ge X, Zhu J, Xuan F, et al. (2014). Identification and mRNA expression of antioxidant enzyme genes associated with the oxidative stress response in the Wuchang bream (Megalobrama amblycephala Yih) in response to acute nitrite exposure. Comp. Biochem. Physiol. C Toxicol. Pharmacol. 159: 69-77.

Tamura K, Dudley J, Nei M and Kumar S (2007). MEGA4: molecular evolutionary genetics analysis (MEGA) software version 4.0. Mol. Biol. Evol. 24: 1596-1599.

Tsutsumi S and Neckers L (2007). Extracellular heat shock protein 90: A role for a molecular chaperone in cell motility and cancer metastasis. Cancer Sci. 98: 1536-1539.

Wei T, Gao Y, Wang R and Xu T (2013). A heat shock protein $90 \beta$ isoform involved in immune response to bacteria challenge and heat shock from Miichthys miiuy. Fish. Shellfish Immunol. 35: 429-437.

Wu CX, Zhao FY, Zhang Y, Zhu YJ, et al. (2012). Overexpression of Hsp90 from grass carp (Ctenopharyngodon idella) increases thermal protection against heat stress. Fish. Shellfish Immunol. 33: 42-47. 